\title{
A Comparative HPLC Analysis of Myricetin, Quercetin and Kaempferol Flavonoids Isolated From Gambian and Indian Moringa oleifera Leaves
}

\author{
Leroy A. Shervington ${ }^{1}$, Bianca Szeaar Li ${ }^{1}$, Amal A. Shervington ${ }^{1}$, Nsima Alpan ${ }^{1}$, Ronak Patel ${ }^{1}$, Usamah Muttakin ${ }^{1}$, \\ Ebrahim Mulla ${ }^{1}$ \\ ${ }^{1}$ School of Pharmacy and Biomedical Sciences, University of Central Lancashire, Preston, PR1 2XT. UK \\ Correspondence: Leroy A. Shervington, School of Pharmacy and Biomedical Sciences, University of Central \\ Lancashire, Preston, PR1 2XT. UK. Email: lashervington@uclan.ac.uk
}

Received: October 2, 2018 Accepted: November 4, 2018 Online Published: November 11, 2018

doi:10.5539/ijc.v10n4p28

URL: https://doi.org/10.5539/ijc.v10n4p28

\begin{abstract}
Moringa oleifera has been used for centuries as a traditional medicine in a number of sub-tropical countries. Recent studies have found it to be rich in flavonoids that exhibit antioxidant activity both in vitro and in vivo. In this study slightly modified conditions were examined in order to maximise the yield of these compounds in particular; Myricetin, Quercetin and Kaempferol. Quantitative analysis of these flavonoids were established using reverse phase ion-pairing High Performance Liquid Chromatography (HPLC) at a wavelength of $370 \mathrm{~nm}$. The method development was carried out following the International Conference for Harmonization guidelines. It was found that refluxing with $0.10 \mathrm{M}$ hydrochloric acid for 24 hour provided high yields of the flavonols (myricetin $292 \mathrm{mg} / \mathrm{kg}$, quercetin $1099 \mathrm{mg} / \mathrm{kg}$ and $\mathrm{kaempferol} 133 \mathrm{mg} / \mathrm{kg}$ ). There was a significant difference in the yield of these flavonols originating from the different geographical locations, with Community Forest Management Farm (CFM Farm) yielding the highest quantity of the flavonols under the conditions applied.
\end{abstract}

Keywords: M. oleifera, HPLC, Flavonoids, Acid hydrolysis, Reverse Phase Ion-Pairing HPLC

\section{Introduction}

Moringa oleifera (M. oleifera), referred to as "the tree of life" is native to the sub-Himalayan regions of India, Pakistan, Bangladesh and various regions of the African continent (Madukwe et al., 2013). Most parts of the plant including the leaves, roots, seeds, bark, fruits and flowers have been found to have nutritional and medicinal properties (Madukwe $e t$ al., 2013). Its nutritional properties have increased its cultivation and harvesting since it's an economically viable food source (Busani et al., 2011). The leaves contain numerous secondary metabolites such as flavonoids and phenolic acids which have recently gained interest for their antioxidant and free radical scavenging properties both in vitro and in vivo (Sankhalkar and Vernekar, 2016). Free radicals or reactive oxygen species (ROS) are generated in the body due to aerobic respiration, infections and metabolism (Halliwell, 2014). They cause oxidative stress to biomolecules and cell structures by damaging lipids, proteins and nucleic acids within cells, initiating numerous physiological and pathological aberrations such as inflammation, cardiovascular disease, carcinogenesis and ageing (Rahal et al., 2014). In addition to their antioxidant properties, it has been found that they exhibit antibacterial, antiviral, anti-inflammatory and anti-carcinogenic properties (El Sohaimy et al., 2015 and Tiloke et al., 2018). M. oleifera leaf extract has also been found to decrease high blood pressure (Aekthammarat et al., 2018).

The flavonoids found in M. oleifera are present as flavonols, a subgroup within the flavonoid family derived from the amino acid phenylalanine at several stages of the phenylpropanoid pathway. The key flavonols present are Myricetin, Quercetin and Kaempferol shown in Figure 1. All three flavonols exist as conjugated chemical structures known as glycosides, linked to one or more sugar molecules via a glycosidic bond. Their bioavailability is dependent on the type of glycoside present within the food source (Saini et al., 2016). The level of flavonols within a particular plant depends on a number of factors such as country of origin, genetic background, method of cultivation, environmental pressures, handling and storage conditions (Rodríguez-Pérez et al., 2015). 
<smiles>[R7]c1cc(-c2oc3cc(O)cc(O)c3c(=O)c2O)cc([R])c1[R]</smiles>

Figure 1. Chemical structures of Myricetin, Quercitin and Kaempferol

\begin{tabular}{l|l|c|c|c}
\hline Flavonol & \multicolumn{1}{|c|}{ IUPAC name } & $\mathbf{R}^{\prime}$ & $\mathbf{R}^{\prime \prime}$ & $\mathbf{R}^{\prime \prime \prime}$ \\
\hline Myricetin & (3,5,7-Trihydroxy-2-(3,4,5-trihydroxyphenyl)-4H-chromen-4-one) & $-\mathrm{OH}$ & $-\mathrm{OH}$ & $-\mathrm{OH}$ \\
\hline Quercetin & (2-(3,4-dihydroxyphenyl)-3,5,7-trihydroxy-4H-chromen-4-one) & $-\mathrm{OH}$ & $-\mathrm{OH}$ & $\mathrm{H}$ \\
\hline Kaempferol & (3,5,7-Trihydroxy-2-(4-hydroxyphenyl)-4H-chromen-4-one) & $-\mathrm{OH}$ & $\mathrm{H}$ & $\mathrm{H}$ \\
\hline
\end{tabular}

Glycosides of myricetin include; Betmidin, Myricetin 3-O-rutinoside, Myricetin-3-O-neohesperidoside and Myricitrin. Myricetin is known to interact with a range of DNA polymerases, RNA polymerases, reverse transcriptases, telomerases, kinases and helicases, supporting its iron-chelating, antioxidant, anti-inflammatory and anti-carcinogenic properties. Reverse transcriptase inhibition activities also implicate it as a possible antiviral drug against Rauscher murine leukemia virus (RLV) and human immunodeficiency virus (HIV) infections (Semwal et al., 2016).

Glycosides of quercetin include; Hyperoside, Isoquercetin, Quercitrin, Rutin and Reinutrin. Quercetin has been found to bind to the following targets resulting in its nutraceutical effects; MEK1 (Apoptosis), PI3K $\gamma$ (Growth arrest), IKK $\alpha / \beta$ (Inflammation) (Caddeo et al., 2016), IRE1-RNAse (Autophagy), Telomerase (Senescence) amongst others (Russo et al., 2012). Some glycosides of quercetin have also been found to reduce serum levels of low-density lipoproteins (LDL) and increase high-density lipoproteins (HDL) in addition to the reduction of triglycerides and free fatty acids, contributing to its cardiovascular disease prevention attributes (Nabavi et al., 2015).

Glycosides of kaempferol include; Kaempferitrin, Kaempferol 3-alpha-D-arabinopyranoside, Robinin, Kaempferol 3-O-rutinoside and Trifolin. Kaempferol has been reported to modulate crucial components in cellular signal transduction pathways associated with apoptosis, angiogenesis, metastasis and inflammation (Saw et al., 2014). Glycosides are conjugates of aglycones with carbohydrates, however to reliably determine the quantity of the flavonols, it is essential to first release them by cleaving the glyosidic bond that links the carbohydrate (Figure 2). The liberation of flavonol aglycones can be carried out via acid hydrolysis. Dilute hydrochloric acid was used as the hydrolysing agent to mimic the hydrolytic process carried out in the stomach, in order to determine approximate concentrations of flavonols present in vivo after ingestion (Zhang et al., 2014).<smiles>CC1OC(O)C2OC1C(Oc1c(-c3cc(O)c(O)c(O)c3)oc3cc(O)cc(O)c3c1=O)C(O)C2O</smiles>

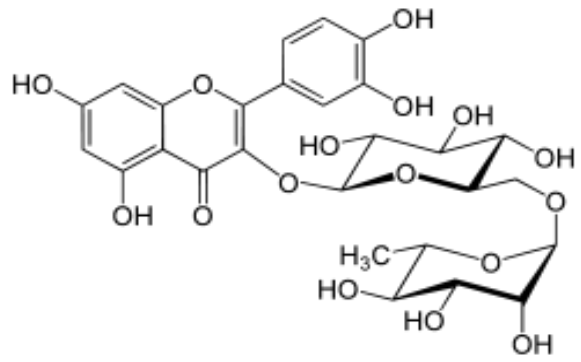

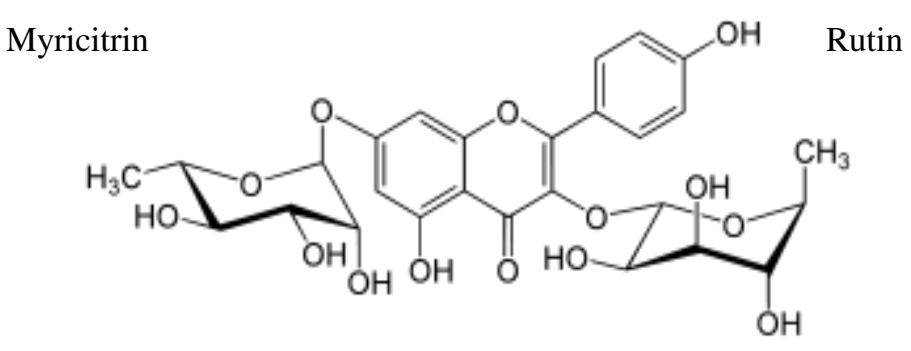

Kaempferitrin

Figure 2. Illustrating the chemical structures of Myricitrin, Rutin and Kaempferitrin, which are glycosides of Myricetin,

Quercetin and Kaempferol, respectively. (Examin.com Inc, 2016). 
High Performance Liquid Chromatography (HPLC) was used to analyse the flavonols in this study. Fortunately, this was possible due to the varying number of hydroxyl groups present on each flavonol, resulting in varying polarities and interactions of the flavonols with the stationary phase. Hence, the three flavonols exhibit different rates of adsorption/desorption, culminating in effective separation. As part of the validation procedure; repeatability, reproducibility, linearity, lower limit of detection (LLOD) and lower limit of quantification (LLOQ) were determined to ensure suitability of the analytical method.

Although there have been numerous studies published detailing the extraction and HPLC analysis of these flavonols from M. oleifera leaves (Biesaga, 2011; Govardhan et al., 2013; Matshediso et al., 2015; Rodríguez-Pérez et al., 2015; Vongsak et al., 2013a \& b), their application was limited because acid hydrolysis was not considered. Wang et al. (2017) compared the extraction procedure using both aqueous and ethanol solutions under reflux conditions in order to determine which of the two methods yielded the highest concentration of flavonols, however, these conditions were not suitable for cleaving the glycosidic bond.

This study aimed at accurately determining the quantity of three flavonols, namely Myricetin, Quercetin and Kaempferol, from the Moringa Oleifera leaves derived from Gambia and India, that would be consumed by one mug averaging $270 \mathrm{~mL}$ and based on the average weight of a tea bag $(5.0 \mathrm{~g})$. The extraction procedure included a simple acid hydrolysis and HPLC was used as the method of analysis of the flavonols of interest, based on an earlier method used by Shervington et al. (2005).

\section{Methods and Materials}

\section{Chemicals}

HPLC grade $(\geq 99.9 \%)$ acetonitrile (ACN), water, absolute ethanol, acetone (Technical Grade), concentrated hydrochloric acid $(\mathrm{HCl})$, citric acid (CA) and Sodium Dodecyl Sulfate (SDS), were all purchased from Fisher Scientific. Analytical standards of Myricetin, Quercetin, Kaempferol and tetrabutylammonium acetate (TBAA) were purchased from Sigma Aldrich.

\section{Plant Leaves From Moringa Oleifera}

The Moringa leaves obtained from Gambia and India were provided by Maxine Shervington and Ronak Patel, respectively. The Gambian batches were obtained from My Farm (2014), CFM Farm (2014), Sanyang (2016), and Sanyano (2014), whereas, the Indian leaves were obtained from Mahadev Faliya Farm (2016) located in the Gujarat region.

\section{Instrumentation and HPLC method}

The High Performance Liquid Chromatography (HPLC) system consisted of a Jasco AS-1555 autosampler system fitted with a UV-2077-Plus UV/Vis detector and a PU-2080-Plus pump. Data was recorded and analysed using Azur 5.0 software installed on a Dell 5150 computer system. Analysis was carried out under an isocratic reverse phase system, using a Waters C18 SymmetryShield $5 \mu 4.60 \times 250 \mathrm{~mm}$ column. The mobile phase consisted of $10 \mathrm{mM}$ SDS, $10 \mathrm{mM}$ TBAA and $25 \mathrm{mM}$ citric acid made up with 60:40 acetonitrile: water. Injection volumes were $20 \mu \mathrm{L}$ and the detection of myricetin, quercetin and kaempferol was measured at $370 \mathrm{~nm}$. The flow rate was set at $1 \mathrm{~mL} / \mathrm{min}$ and each run of the extracted samples, derived from the leaves treated under reflux temperatures in dilute hydrochloric acid, was for a period of 30 minutes at ambient temperature.

\section{Preparation of mobile phase and solvent}

Mobile phase $(1000 \mathrm{~mL})$ was prepared by mixing acetonitrile $(550 \mathrm{~mL})$ with HPLC grade water $(400 \mathrm{~mL})$ in a $1000 \mathrm{~mL}$ volumetric flask. To the mixture was added SDS $(10 \mathrm{mM})$, TBAA $(10 \mathrm{mM})$ and CA $(25 \mathrm{mM})$ and to ensure that all three components had solubilized, the flask was placed into a sonicator water bath, cooled and made up to the meniscus with acetonitrile $(50 \mathrm{~mL})$. The solvent that was used to solubilise the analytical standards and used to dilute the plant extracts, consisted of HPLC grade acetonitrile: water (60:40). This mixture is defined as solvent A throughout the paper.

\section{Preparation and purity of the analytical standards}

Each flavonol standard was prepared by weighing out myricetin $(10 \mathrm{mg})$, quercetin $(10 \mathrm{mg})$ and kaempferol $(10 \mathrm{mg})$ in a $100 \mathrm{~mL}$ volumetric flask, solubilizing them in solvent A and making up to the mark with the same solvent, resulting in the three flavanols, myricetin, quercetin and kaempferol, at concentrations of $314.22 \mu \mathrm{M}, 330.86 \mu \mathrm{M}$ and $349.36 \mu \mathrm{M}$, respectively. These solutions were referred to as the standard stock solutions.

\section{Method Validation}

\section{Repeatability}

Stock solutions (10 mg/100 mL) of the standards were diluted 1:1 using solvent A. Myricetin, quercetin and kaempferol 
at concentrations of $157.11,165.43$ and $174.68 \mu \mathrm{M}$, respectively, were used to carryout repeatability. Each solution was injected six times and the corresponding peak area (PA) and relative standard deviation (RSD) were determined.

\section{Reproducibility}

Six solutions of myricetin, quercetin and kaempferol at concentrations of $157.11,165.43$ and $174.68 \mu \mathrm{M}$, respectively, were prepared and injected twice and the average PA and RSD were determined.

\section{Linearity}

Five concentrations of each of the flavonoids were prepared from the standard stock solutions $(1,2,4,6$ and $10 \mathrm{mg} / 100$ $\mathrm{mL})$. Each sample was analysed twice, calibration curves were plotted and the coefficients of determination $\left(\mathrm{R}^{2}\right)$ and regression were obtained.

\section{Lower Limit of Detection and Lower Limit of Quantification (LLOD and LLOQ)}

All three stock solutions were repeatedly diluted down by a factor of 2 and each diluted solution was analysed twice until the LLOD was established. The LLOD was identified as the lowest concentration analysed that differentiated between the response of the sample and the background noise. The LLOQ was achieved by determining the lowest concentration that provided repeatable peak area responses in triplicate with \% RSD between 2 and 3 .

\section{General procedure for the extraction and analysis of $M$. oleifera leaves}

The batches of the Moringa oleifera leaves were each subjected to reflux conditions that involved the use of hydrochloric acid at concentrations of $0.10 \mathrm{M}$ or $1.0 \mathrm{M}$. The reflux times involving the use of $0.10 \mathrm{M}$ hydrochloric acid were 3,13 and 24 hours, whereas, the reflux conditions using 1.0 M hydrochloric acid were only carried out over a 3 hour period. Batches from CFM Farm, Sanyano and My Farm were only treated with 0.10 M hydrochloric acid in order to compare findings carried out in our lab (unpublished work).

The Moringa oleifera leaves $(5.0 \mathrm{~g}$ ) was carefully transferred to a $500 \mathrm{ml}$ round bottom flask and dilute hydrochloric acid $(270 \mathrm{~mL})$ was added to the flask with the addition of a magnetic flea. The flask was connected to a condenser and the mixture was heated to mild reflux $\left(90^{\circ} \mathrm{C}\right)$ on a magnetic stirrer and after the allotted time, the dark red solution was allowed to cool to room temperature and approximately $100 \mathrm{~mL}$ was carefully transferred to a $250 \mathrm{~mL}$ conical flask using a filtered funnel. For the reactions that involved using $0.10 \mathrm{M}$ hydrochloric acid, a 1 in 10 dilution was carried out using solvent $\mathrm{A}$, whereas, a 1 in 100 dilution was carried out for the reactions that involved $1.0 \mathrm{M}$ hydrochloric acid. The main reason for carrying out these dilutions was to maintain the integrity of the HPLC column. The samples were analysed using an automated injection system and each run was programmed for 30 minutes. To help in elucidating and confirming the presence of specific flavonols, spiking of samples were also carried out as part of the analysis using relevant standards.

\section{Results and Discussion}

All three flavonol standards were tested for repeatability as described in the method, and the results are summarized in Table 1. The International Conference for Harmonization (ICH) declares that the \% RSD should not exceed $2 \%$ over six injections for it to be acceptable (ICH, 2014), all three standards were found to be below 1\% RSD. The standards were tested for reproducibility and the \% RSD for the 6 samples of all three standards were below $2 \%$, demonstrating a high degree of reproducibility. These results are summarised in Table 2.

Table 1. Repeatability data for Myricetin, Quercetin and Kaempferol

\begin{tabular}{c|c|c|c}
\hline Flavonol & Concentrations $(\boldsymbol{\mu M})$ & Average Peak Area & \% RSD $(\mathbf{n}=\mathbf{6})$ \\
\hline Myricetin & 157.11 & 3068.11 & 0.53 \\
\hline Quercetin & 165.43 & 3621.60 & 0.88 \\
\hline Kaempferol & 174.68 & 3374.14 & 0.11 \\
\hline
\end{tabular}

Table 2. Reproducibility data for Myricetin, Quercetin and Kaempferol

\begin{tabular}{c|c|c|c}
\hline Flavonol & Concentrations $(\boldsymbol{\mu M})$ & Average Peak Area & \% RSD (n=6) \\
\hline Myricetin & 157.11 & 2976.36 & 0.93 \\
\hline Quercetin & 165.43 & 3811.52 & 0.20 \\
\hline Kaempferol & 174.68 & 3374.76 & 0.26 \\
\hline
\end{tabular}


Following the ICH guidelines, five concentrations of all three standards were prepared and analysed for linearity and the data is summarized in Table 3. All three flavonols showed linearity within the range of concentrations used. The coefficient of determination $\mathrm{R}^{2}$ for myricetin, quercetin and kaempferol were $0.9995,0.9998$ and 0.9997 , respectively. The results are summarized in Table 3. It was important to be able to detect and quantify the flavonols at very low concentrations and therefore the LLOD and LLOQ were determined using the procedures described in the method and the results are summarised in Table 4. Myricetin, quercetin and kaempferol were reliably quantified at concentrations of $15.34,16.15$ and $17.06 \eta \mathrm{M}$, respectively.

Table 3. Linearity data across five concentrations of Myricetin, Quercetin and Kaempferol

\begin{tabular}{l|c|c|c}
\hline Flavonol & Concentrations $(\boldsymbol{\mu M})$ & Regression equation & Coefficient of determination $\mathbf{R}^{\mathbf{2}}$ \\
\hline Myricetin & $31.42,62.85,125.69,188.54,314.23$ & $\mathrm{y}=20.017 \mathrm{x}-124.27$ & 0.9995 \\
\hline Quercetin & $33.09,66.17,132.35,198.52,330.86$ & $\mathrm{y}=20.357 \mathrm{x}+55.87$ & 0.9998 \\
\hline Kaempferol & $34.94,69.87,139.74,209.61,349.36$ & $\mathrm{y}=18.703 \mathrm{x}+58.14$ & 0.9997 \\
\hline
\end{tabular}

Table 4. Lower Limit of Detection (LLOD) and Lower Limit of Quantification (LLOQ) of the three flavonols

\begin{tabular}{c|c|c|c}
\hline Flavonol & $($ LLOD $(\boldsymbol{\eta} M)(\mathbf{n}=3)$ & \% RSD & LLOD $(\boldsymbol{\eta} M)(\mathbf{n = 2})$ \\
\hline Myricetin & 15.34 & 2.67 & 7.67 \\
\hline Quercetin & 16.15 & 2.44 & 8.08 \\
\hline Kaempferol & 17.06 & 1.32 & 4.26 \\
\hline
\end{tabular}

Figure 3 shows chromatograms of myricetin, quercetin and kaempferol standards and a chromatogram showing the separation of all three flavonoid standards. Interestingly, although the chemical structure of the three flavonoids are similar, they are readily resolved on the column due to the effect the hydroxyl groups have on polarity (see Figure 1). Myricetin, quercetin and kaempferol, were found to elute at average retention times of 3.60, 4.80 and 6.90 minutes, respectively and therefore readily resolved.

A

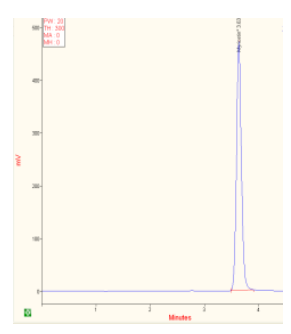

B

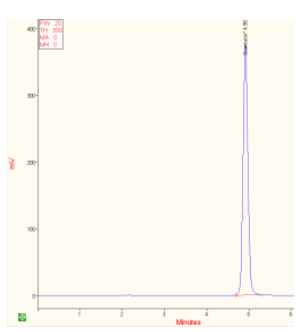

$\mathrm{C}$

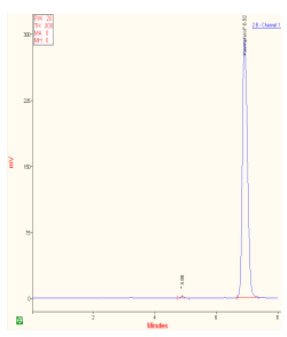

$\mathrm{E}$

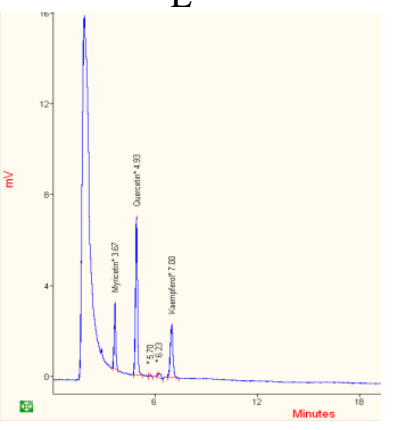

$\mathrm{D}$

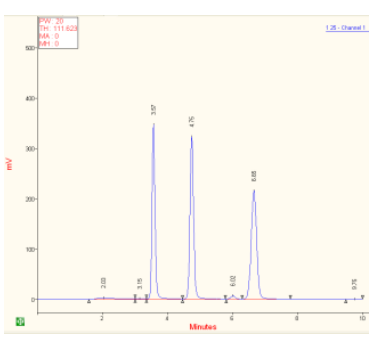

Figure 3. A typical chromatogram for myricetin analytical standard at $157.11 \mu \mathrm{M}(\mathrm{A})$, quercetin analytical standard at $165.43 \mu \mathrm{M}(\mathrm{B})$ and kaempferol analytical standard at $174.68 \mu \mathrm{M}(\mathrm{C})$, the mixture of the three analytical standards, myricetin (3.6 $\mathrm{min})$, quercetin $(4.8 \mathrm{~min}$ ) and kaempferol $(6.7 \mathrm{~min})(\mathrm{D})$, typical chromatogram of Indian (Mahadev Faliya Farm) extract employing mild reflux in $0.10 \mathrm{M} \mathrm{HCl}$ for 13 hours (E). 
All Moringa oleifera batches that included Sanyang, Mahadev Faliya Farm, My Farm, Sanyano and CFM Farm were treated under reflux conditions in $0.10 \mathrm{M}$ hydrochloric for 3 hour. It was found that under these conditions, only quercetin and kaempferol could be accurately quantified (shown in Figure 4). Interestingly, the leaves originating from CFM Farm yielded the highest concentration of quercetin $(2045.01 \mathrm{mg} / \mathrm{kg}$ ), while Sanyano yielded the highest concentration of kaempferol $(314.01 \mathrm{mg} / \mathrm{kg})$. Myricetin appeared to be absent under this condition, however, at either higher concentrations of acid or after applying longer reflux times, myricetin was detected and quantified (Figures $5 \&$ 6).

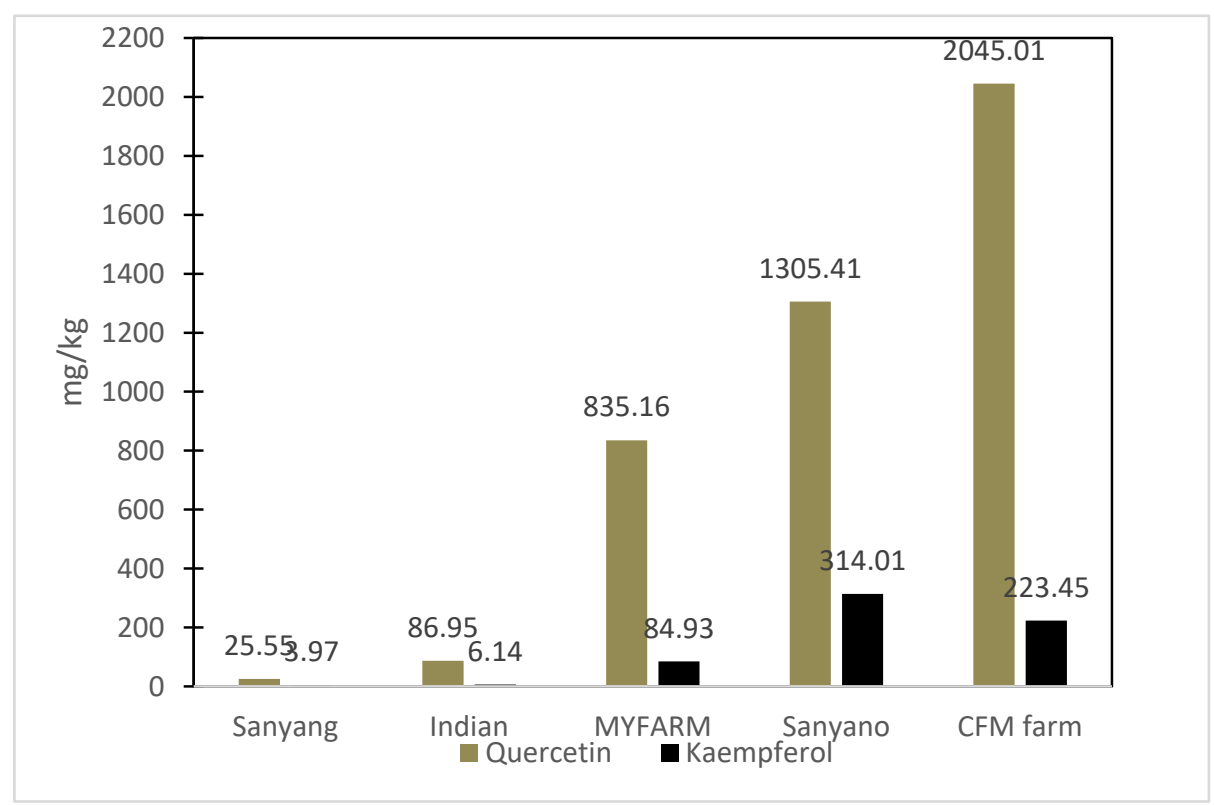

Figure 4. Shows the concentrations $(\mathrm{mg} / \mathrm{kg}$ ) of flavonols extracted by $0.1 \mathrm{M} \mathrm{HCl}$ for 3 hours, originating from various geographical locations

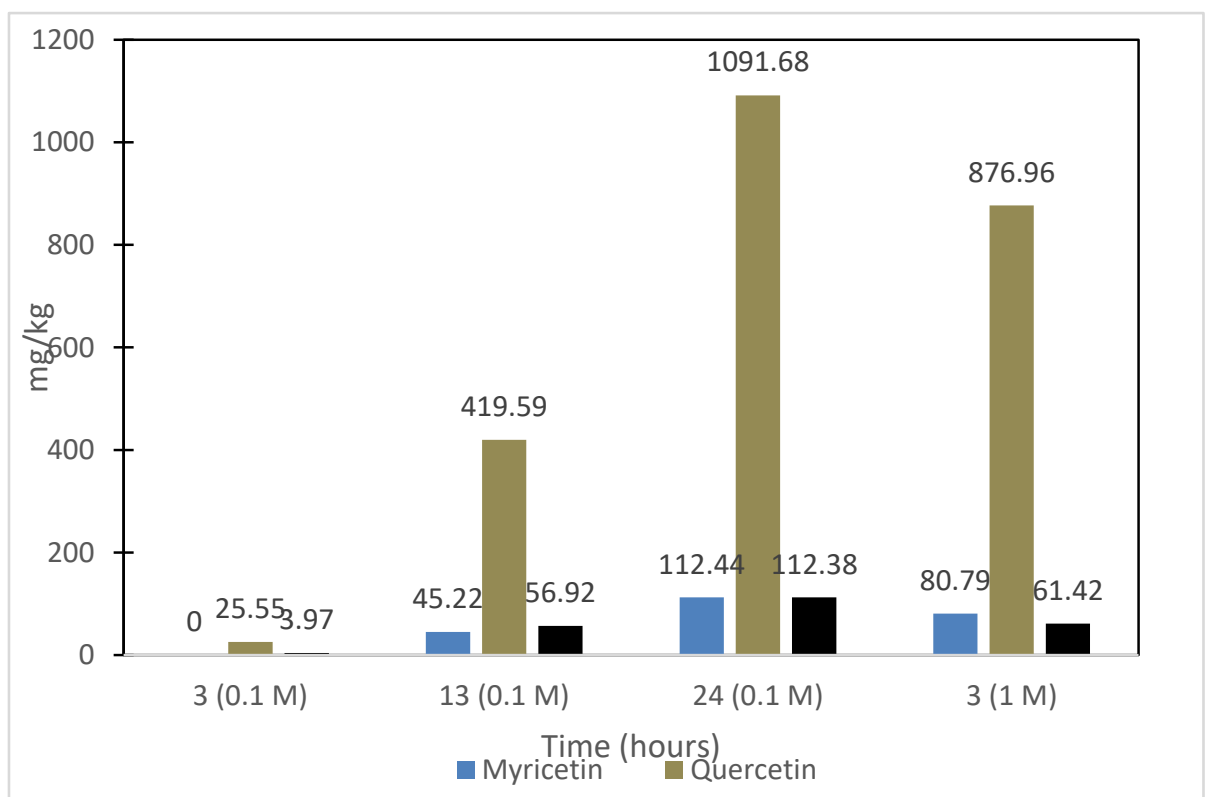

Figure 5. Shows the concentrations ( $\mathrm{mg} / \mathrm{kg}$ ) of flavonols extracted using the listed conditions for the Gambian (Sanyang) leaves 


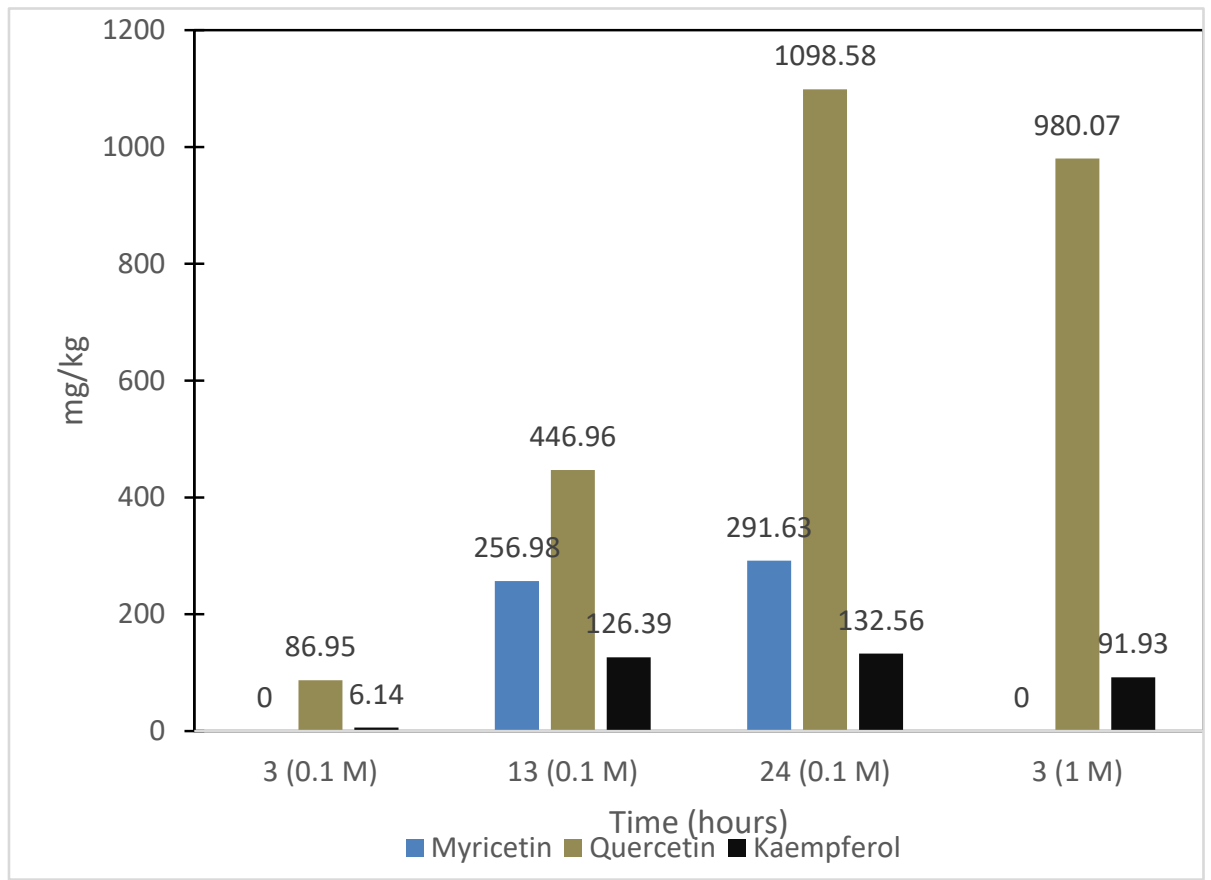

Figure 6. Shows the concentrations $(\mathrm{mg} / \mathrm{kg}$ ) of flavonols extracted using the listed conditions for the Indian (Mahadev Faliya Farm) leaves

It was decided that due to the relatively low yield of the flavonols derived from the Gambian (Sanyang) and Indian (Mahadev Faliya Farm) leaves under these conditions and due to the fact that these batches were grown, cultivated and harvested during the same year, on two continents, attention was directed at investigating the appropriate extraction conditions that could possibly provide a more reliable indication of the flavonol content from these two sources.

The two sources of leaves were treated under mild reflux with $0.10 \mathrm{M}$ hydrochloric acid for periods of 3,13 and 24 hours. The two sources of leaves were also treated with 1.0 M hydrochloric acid but was limited to only 3 hours of mild reflux in order to limit possible undesirable degradation.

It was found that the highest yield of flavonols for both sources was achieved by mild refluxing the leaves in $0.10 \mathrm{M}$ hydrochloric acid for a total of 24 hours. The Indian (Mahadev Faliya Farm) leaves, yielded myricetin, quercetin and kaempferol at concentrations of $292 \mathrm{mg} / \mathrm{kg}, 1099 \mathrm{mg} / \mathrm{kg}$ and $133 \mathrm{mg} / \mathrm{kg}$, respectively, while the Gambian (Sanyang) leaves yielded myricetin, quercetin and kaempferol at concentrations of $112 \mathrm{mg} / \mathrm{kg}, 1092 \mathrm{mg} / \mathrm{kg}$ and $112 \mathrm{mg} / \mathrm{kg}$, respectively. From these findings, it would appear that the concentration of myricetin from the Indian leaves is at least twofold that found in the Gambian leaves and the kaempferol from the Indian leaves is slightly higher with at least a 1.2 fold to that found in the Gambian source. Interestingly, both sources yielded similar concentrations of quercetin.

Considering the approximate quantity of these flavonols obtained from a mug of tea (volume of $270 \mathrm{~mL}$ ) prepared from the leaves cultivated in India (Mahadev Faliya Farm), the quantity of myricetin, quercetin and kaempferol consumed would be $1.46 \mathrm{mg}, 5.50 \mathrm{mg}$ and $0.67 \mathrm{mg}$, respectively, while the quantity of myricetin, quercetin and kaempferol consumed from the Gambian (Sanyang) would be $0.56 \mathrm{mg}, 5.46 \mathrm{mg}$ and $0.56 \mathrm{mg}$, respectively. If these teas were habitually consumed at least three times daily, the myricetin, quercetin and kaempferol (Mahadev Faliya Farm) would amount to $4.38 \mathrm{mg}, 16.5 \mathrm{mg}$ and $2.10 \mathrm{mg}$, respectively, while the myricetin, quercetin and kaempferol (Sanyang) would amount to $1.68 \mathrm{mg}, 16.38 \mathrm{mg}$ and $1.68 \mathrm{mg}$, respectively. These values are not far from the values reported by Vogiatzoglou et al; 2015 who estimated the mean intake on a daily basis of myricetin, quercetin and kaempferol in adults ranging from 18 to 64 years of age (involving 14 European countries) approximates to $2 \pm 0 \mathrm{mg}, 14 \pm 1 \mathrm{mg}$ and 5 $\pm 1 \mathrm{mg}$, respectively.

The extraction procedures were carried out twice and can therefore be defined as preliminary studies. In order to optimize the findings, it would require the investigation to be carried out on a larger number of batches from both geographical regions in order to achieve statistical significance.

It was interesting to find that all five M. oleifera species yielded a higher concentration of quercetin compared to the other two flavonols, implying that it is the most abundant of the three flavonols found in the M. oleifera species (Saini 
et al., 2016), and supports the plants benefits with regard to reducing cardiovascular diseases (Nabavi et al., 2015).

The results obtained from this study indicate that varying yields of flavonols were found compared to studies reported by Matshediso et al. (2015), who achieved concentrations ranging from $406-2699 \mathrm{mg} / \mathrm{kg}$ (myricetin), $840-1488 \mathrm{mg} / \mathrm{kg}$ (quercetin) and 1730-3440 mg/kg (kaempferol), however, they employed a pressurised hot water extraction method which appeared to be a more suitable procedure with respect to improved yields but at higher costs (Nuapia et al., 2018 and Hamany Djande et al., 2018). However, under these conditions there is an increased risk of degradation of the flavonols. Agroclimatic locations need to be considered when comparing yields since the leaves used in their investigation were grown and harvested in South Africa (Kumar and Pandey, 2013). Furthermore, a comparison with other studies needs to consider factors such as maturity, post-harvest handling and processing/storage of the plants (Abdulkadir et al., 2015).

One drawback experienced with the present study was that involving the separation of myricetin from the crude extract of the Gambian source, fortunately, it was resolved by applying the Azur software option that enabled an accurate estimation of myricetin.

\section{Conclusions}

A reverse phase ion-pairing HPLC method of analysis was employed to separate and quantify myricetin, quercetin and kaempferol from the M. oleifera plant. The optimal conditions for obtaining high yields of flavonols involved refluxing the leaves in $0.10 \mathrm{M}$ hydrochloric acid for a period of 24 hours. The hydrolytic procedure resulted in cleaving the glycosidic bonds, releasing the flavonol in the process. This procedure is necessary in bringing about the separation of the flavonols in question, and thus, highlights possible discrepancies in reports that claim to accurately detect and quantify myricetin, quercetin and kaempferol without subjecting the conjugated molecule, known as a glycoside, to hydrolytic cleavage.

It is not surprising to find that $M$. oleifera grown in the different geographical regions, exhibit varying concentrations of specific flavonols. This phenomena was conveniently demonstrated in this investigation, where it was found that the Indian source exhibited at least a two fold difference in the quantity of myricetin compared to the Gambian source. An interesting project would be to carry out an extensive study of the leaves of the M. oleifera plant grown worldwide in order to compare the flavonol content using the same extraction procedures applied in this investigation. The information gained could possibly be utilized by the nutraceutical industry, interested in isolating these flavonols for commercial use.

\section{Acknowledgements}

The authors would like to thank Maxine Shervington and Ronak Patel for providing the Moringa oleifera samples from Gambia and India, respectively, and the School of Pharmacy and Biomedical Science, University of Central Lancashire for providing the support in order to carry out the investigation. We would also like to thank Louis Turrell, Tommy Leung, Jose Dennis, Omonzoya Iyobhebhe, Joseline Larbi and Tonderai Sachikunda, for their contributions to the investigation.

\section{References}

Abdulkadir, I. S., Nasir, I. A., Sofowora, A., Yahaya, F., Ahmad, A. A., \& Hassan, I. A. (2015). Phytochemical Screening and Antimicrobial Activities of Ethanolic Extracts of Moringa oleifera Lam on Isolate of Some Pathogens. J. App Pharm, 7, 203. https://doi.org/10.4172/1920-4159.1000203

Aekthammarat, D., Pannangpetch, P., \& Tangsucharit, P. (2018). Moringa oleifera leaf extract lowers high blood pressure by alleviating vascular dysfunction and decreasing oxidative stress in L-NAME hypertensive rats. Phytomedicine. https://doi.org/10.1016/j.phymed.2018.10.023

Biesaga, M. (2011). Influence of extraction methods on stability of flavonoids. J. Chroma A 1218, 2505-2512. https://doi.org/10.1016/j.chroma.2011.02.059

Busani, M., Patrick, J., Arnold, H., \& Voster, M. (2011). Nutritional characterization of Moringa (Moringa oleifera Lam.) leaves. African Journal of Biotechnology, 10(60), 12925-12933. https://doi.org/10.5897/AJB10.1599

Caddeo, C., Nacher, A., Vassallo, A., Armentano, M., Pons, R., Fernàndez-Busquets, X., \& Manconi, M. (2016). Effect of quercetin and resveratrol co-incorporated in liposomes against inflammatory/oxidative response associated with skin cancer. International Journal of Pharmaceutics, 513(1-2), 153-163. https://doi.org/10.1016/j.ijpharm.2016.09.014

El Sohaimy, S., Hamad, G., Mohamed, S., Amar, M., \& Al-Hindi, R. (2015). Biochemical and functional properties of M. oleifera leaves and their potential as a functional food. Global Adv. Res. J. Agric. Sci, 4, 188-199. 
Govardhan, S. R., Negi, P., \& Radha, C. (2015). Phenolic composition, antioxidant and antimicrobial activities of free and bound phenolic extracts of Moringa oleifera seed flour. J. Functional Foods, 5, 1883-1891. https://doi.org/10.1016/j.jff.2013.09.009

Halliwell, B. (2014). Cell culture, oxidative stress, and antioxidants: Avoiding pitfalls. Biomedical J, 37(3), 99. https://doi.org/10.4103/2319-4170.128725

Hamany, D. C., Piater, L., Steenkamp, P., Madala, N., \& Dubery, I. (2018). Differential extraction of phytochemicals from the multipurpose tree, Moringa oleifera, using green extraction solvents. South African Journal of Botany, 115, 81-89. https://doi.org/10.1016/j.sajb.2018.01.009

ICH, Q2 (R1) (2014) Validation of analytical procedures: text and methodology.

Kumar, S., \& Pandey, A. (2013). Chemistry and Biological Activities of Flavonoids: An Overview. The Scientific World Journal, 1-16. https://doi.org/10.1155/2013/162750

Madukwe, E., Ezeugwu, J., \& Eme, P. (2013). Nutrient Composition and Sensory Evaluation of Dry Moringa Oleifera Aqueous Extract. Int. J. of Basic \& Applied Sciences, 13, 100-102.

Matshediso, P., Cukrowska, E., \& Chimuka, L. (2015) Development of pressurised hot water extraction (PHWE) for essential compounds from Moringa oleifera leaf extracts. Food Chemistry, 172, 423-427. https://doi.org/10.1016/j.foodchem.2014.09.047

Nabavi, S., Russo, G., Daglia, M., \& Nabavi, S. (2015). Role of quercetin as an alternative for obesity treatment: You are what you eat!. Food Chemistry, 179, 305-310. https://doi.org/10.1016/j.foodchem.2015.02.006

Nuapia, Y., Cukrowska, E., Tutu, H., \& Chimuka, L. (2018). Statistical comparison of two modeling methods on pressurized hot water extraction of vitamin $\mathrm{C}$ and phenolic compounds from Moringa oleifera leaves. South African Journal of Botany. https://doi.org/10.1016/j.sajb.2018.09.001.

Rahal, A., Kumar, A., Singh, V., Yadav, B., Tiwari, R., Chakraborty, S., \& Dhama, K. (2014). Oxidative Stress, Prooxidants, and Antioxidants: The Interplay. BioMed Research International, 2014, 1-19. https://doi.org/10.1155/2014/761264

Rodríguez-Pérez, C., Quirantes-Piné, R., Fernández-Gutiérrez, A., \& Segura-Carretero, A. (2015). Optimization of extraction method to obtain a phenolic compounds-rich extract from Moringa oleifera Lam leaves. Industrial Crops and Products, 66, 246-254. https://doi.org/10.1016/j.indcrop.2015.01.002

Russo, M., Spagnuolo, C., Tedesco, I., Bilotto, S., \& Russo, G. (2012). The flavonoid quercetin in disease prevention and therapy: Facts \& fancies. Bioch. Pharm, 83, 6-15. https://doi.org/10.1016/j.bcp.2011.08.010

Saini, R., Sivanesan, I., \& Keum, Y. (2016). Phytochemicals of Moringa oleifera: a review of their nutritional, therapeutic and industrial significance. 3 Biotech, 6, 203.

Sankhalkar, S., \& Vernekar, V. (2016). Quantitative and Qualitative analysis of Phenolic and Flavonoid content in Moringa oleifera Lam and Ocimum tenuiflorum L. Pharmaco. Res., 8, 16.

Saw, C., Guo, Y., Yang, A., Paredes-Gonzalez, X., Ramirez, C., Pung, D., \& Kong, Ah-Ng, T. (2014). The berry constituents quercetin, kaempferol, and pterostilbene synergistically attenuate reactive oxygen species: Involvement of the Nrf2-ARE signaling pathway. Food Chem Toxicol., 72, 303-311. https://doi.org/10.1016/j.fct.2014.07.038

Semwal, D., Semwal, R., Combrinck, S., \& Viljoen, A. (2016). A Dietary Molecule with Diverse Biological Activities. Nutrients, 8, 90. https://doi.org/10.3390/nu8020090

Shervington, L., Abba, M., Hussain, B., \& Donnelly, J. (2005). The simultaneous separation and determination of five quinolone antibotics using isocratic reversed-phase HPLC: Application to stability studies on an ofloxacin tablet formulation. J. Pharma. Biomedical Anal, 39, 769-775. https://doi.org/10.1016/j.jpba.2005.04.039

Tiloke, C., Anand, K., Gengan, R., \& Chuturgoon, A. (2018). Moringa oleifera and their phytonanoparticles: Potential antiproliferative agents against cancer. Biomedicine \& Pharmacotherapy, 108, 457-466. https://doi.org/10.1016/j.biopha.2018.09.060

Vogiatzoglou, A., Mulligan, A. A., Lentjes, M. A. H., Luben, R. N., Spencer, J. P. E., et al. (2015) Flavonoid Intake in European Adults (18 to 64). PLoS ONE 10(5): e0128132.

Vongsak, B., Sithisarn, P., \& Gritsanapan, W. (2013a). Simultaneous HPLC Quantitative Analysis of Active Compounds in Leaves of Moringa oleifera, J. Chroma. Sci., 52, 641-645. https://doi.org/10.1093/chromsci/bmt093

Vongsak, B., Sithisarn, P., Mangmool, S., Thongpraditchote, S., Wongkrajang, Y., \& Gritsanapan, W. (2013b). 
Maximizing total phenolics, total flavonoids contents and antioxidant activity of Moringa oleifera leaf extract by the appropriate extraction method. Industrial Crops and Products, 44, 566-571. https://doi.org/10.1016/j.indcrop.2012.09.021

Wang, Y., Gao, Y., Ding, H., Liu, S., Han, X., Gui, J., \& Liu, D. (2017). Subcritical ethanol extraction of flavonoids from Moringa oleifera leaf and evaluation of antioxidant activity. Food Chemistry, 218, 152-158. https://doi.org/10.1016/j.foodchem.2016.09.058

Zhang, W., Chen, J., Lam, K., Zhan, J., Yao, P., Dong, T., \& Tsim, K. (2014) Hydrolysis of Glycosidic Flavonoids during the Preparation of Danggui Buxue Tang: An Outcome of Moderate Boiling of Chinese Herbal Mixture. Evidence-Based complementary and Alternative Medicine, 2014, 1-11. https://doi.org/10.1155/2014/546097

\section{Copyrights}

Copyright for this article is retained by the author(s), with first publication rights granted to the journal.

This is an open-access article distributed under the terms and conditions of the Creative Commons Attribution license (http://creativecommons.org/licenses/by/4.0/). 